\title{
ASSESSMENT OF THE RELATIONSHIP OF SERUM AND SALIVARY PARAMETERS IN CHILDREN UNDERGOING HEMODIALYSIS
}

\author{
Aliaa A.Hamouda ${ }^{1} B D S$, Aly A.Sharaf ${ }^{2} P h D$, Hanan M.Fathy ${ }^{3} P h D$, Neveen L.Mikhael ${ }^{4}$
}

$P h D$.

\begin{abstract}
INTRODUCTION: Various metabolic changes were elaborated in patients with chronic kidney disease which often require biochemical analysis of blood regularly. Saliva analysis has many advantages as an alternative to blood analysis.

OBJECTIVE: Evaluate levels of some parameters in saliva and serum including: urea, creatinine, calcium and phosphorus in children undergoing hemodialysis and to determine the correlation between saliva and serum regarding these parameters in order to evaluate salivary diagnostic potential. MATERIALS AND METHODS: A cross sectional analytical study was conducted on children undergoing hemodialysis in Alexandria University Children's Hospital (AUCH). A total of 20 patients were included in the present study of whom, 10 were boys (50\%) and 10 were girls (50\%) with a mean age $8.85 \pm 2.74$. Serum and salivary samples were collected from the participants for analysis. Serum tests including Urea, creatinine (Cr), calcium (Ca), phosphorus (P) and salivary tests including Urea, Cr, Ca and P were recorded in all subjects.

RESULTS: There was significant a positive correlation $(\mathrm{P}<0.0001)$ between serum and salivary urea $(\mathrm{r}=0.79)$, as well as between serum and salivary creatinine $(r=0.68)$. Besides, levels of phosphorus were significantly higher in saliva than in serum. However, levels of creatinine and calcium showed significantly lower levels in saliva compared to serum.

CONCLUSION: Outcomes of this study found that analysis of salivary creatinine and urea in patients with chronic kidney disease mirrored their levels in serum. Consequently, salivary creatinine and urea levels could be used non-invasively to measure serum urea and creatinine levels respectively in patients with chronic kidney disease which may be helpful in monitoring of these patients.
\end{abstract}

KEYWORDS: salivary parameters, serum parameters, children, chronic kidney disease, hemodialysis.

1- Demonstrator at Department of Pediatric Dentistry and Dental Public Health, Faculty of Dentistry, Alexandria University, Egypt,

2- Professor at Department of Pediatric Dentistry and Dental Public Health, Faculty of Dentistry, Alexandria University, Egypt

3- Assistant Professor at Department of Pediatrics, Faculty of Medicine, Alexandria University, Egypt

4- Lecturer at Department of Clinical Pathology, Faculty of Medicine, Alexandria University, Egypt.

*Corresponding author:

alia.abdelsalam205@icloud.com

\section{INTRODUCTION}

Chronic kidney disease (CKD) is a major global health problem with increasing incidence and prevalence (1). It is a condition in which a preliminary injury is followed by gradual decrease in the kidney function, that in most severe cases, eventually leads to the need for renal replacement therapy (2).

The prevalence of CKD has considerably increased given that its survival and treatment has been noticeably upgraded (3). A systematic review and meta-analysis was done in 2016 by Hill et al which estimated the global prevalence of CKD to be between 11 and 13\% worldwide(4). Review of the available literature showed very limited information on prevalence in the pediatric population. Although, in 2008 the prevalence of children on Renal
Replacement Therapy (RRT) was estimated globally to be 18 to 100 per million of the age-related population (5). Even though, epidemiological data on CKD may underrate its actual incidence and prevalence, as patients are often clinically asymptomatic, particularly in its initial stages. Another possible explanation for the limited information on the epidemiology of CKD especially in the pediatric population is the historical absence of a generic definition and precise classification of CKD.

Biochemical laboratory investigations are a fundamental part in detecting and monitoring diseases. For biochemical analysis, different biological fluids or tissues are collected, however, blood is still the most widely used diagnostic sample $(6,7)$. Laboratory follow-up is very important for maintainning homeostasis, assessing the adequacy of dialysis, the need for further treatment lines and 
improvement of the quality of life for CKD children which is known to affect all body systems (8).

Since blood is held up as "the gold standard", being the most common sample in clinical chemistry, measurement of Urea, Creatinine (Cr), Alkaline phosphatase (ALP), Calcium (Ca), Phosphorus (Ph), Sodium (Na), Potassium (K) and Hemoglobin $(\mathrm{Hb})$ are characteristic laboratory blood tests in patients with renal diseases.(9) However, rigorous laboratory follow up necessitates constant blood sampling. In most cases there is anemia related to this disease resulting from decreased erythrocyte production, iron sequestration, protein malnutrition (from lack of appetite and being on a diet not meeting their protein needs to meet the ability to make hemoglobin) and loss of blood (related to uremic gastritisinduced gastrointestinal bleeding), hence constant blood sampling may worsen already existing anemia.(9) Unfortunately, collection of blood samples is an invasive practice that may comprise some hazard to the health of medical staff and patients as well as being a source of discomfort in a number of populations and situations, especially when dealing with pediatric population or special needs patients. Moreover, the need for special equipment and well trained personnel makes the sampling process very expensive. Concerning all these disadvantages of blood sampling it was important to try to find a reliable alternate to serum sampling.Therefore, interest in a less invasive , rapid and reliable diagnostic test has been grown exponentially in the past decade; which directed considerable amount of researches on using salivary sample analysis as a biological fluid for monitoring and detection of systemic diseases $(6,7)$.

Kidney diseases can be diagnosed via clinical symptoms, laboratory examinations, image analysis, or biochemical analysis of blood and/or urine samples which can show broad series of biomarkers that play a key role in the diagnosis and assessment of the risk of CKD. Although glomerular filteration rate (GFR) is now thought to be the best indicator of CKD, the accuracy of diagnosis is altered by acceptance of various formulas. Furthermore, urine sample collection is uncomfortable for some patients, and blood serum analysis is often unsuitable due to the invasive procedure and the related risk of infection. It also causes anxiety among patients particulary in pediatric patients. Therefore, if it is achievable to get analogous or identical information to offer an accurate evaluation and monitoring of disease status from saliva sample that is a noninvasive diagnostic medium, this would be highly adventageous (10). A survey reported that dentists believe that screening for medical conditions is important and they are willing to participate when the sample is saliva (11).

The importance of saliva as a diagnostic fluid has attracted interest in recent years. In fact, human saliva offers several advantages compared to traditional blood-based biochemical analysis including; easy availability, noninvasiveness, stress-free sampling , minimal risk of contracting infections, the close relationship between saliva and serum parameters as well as low cost of collection and processing which make it an ideal biofluid for developing countries. These advantages have attracted the interest of researchers in saliva as a unique fluid for diagnosing various diseases and in their management $(12,13)$. Collection of saliva is undemanding, rapid, and easier to handle and store than blood sampling, as it does not have the property of clotting (14).These properties increase the role of saliva in current diagnostic methods. Furthermore, there are certain biomarkers present in saliva which are specific for certain diseases. These biomarkers increase the role of saliva in the field of diagnostics (15).

In spite of the attractive nature of saliva and its undeniable advantages as a diagnostic sample, it is still largely ignored as a diagnostic fluid due to a set of limitations including individual's physiological variations, type of the collected saliva and genetic differences (16). Moreover, saliva as a diagnostic fluid is often criticized based on the fact that biomarkers are present in amounts that are very low to be detected reliably. However; this is no longer a limitation due to advancement in detection techniques (17).

The aim of this study was to assess the reliability of saliva as an alternative to serum in managing children undergoing hemodialysis by assessing the correlation between serum and salivary parameters. It was hypothesized that there is no correlation between serum and salivary parameters in children undergoing hemodialysis.

\section{MATERIALS AND METHODS:}

A cross sectional analytical study was conducted on children undergoing hemodialysis in Alexandria University Children's Hospital (AUCH) to determine the correlation between serum and salivary parameters in these patients.

\section{Eligibility criteria}

The participants enrolled in this study were selected after fulfilling the following criteria:

- All patients had end-stage renal failure (2) diagnosed by a nephrologist and were undergoing hemodialysis in AUCH.

- Age ranged between 3-12 years.

- Parents / caregivers agreed to give consent.

The approval of the Research Ethics Committee of the Faculty of Dentistry, Alexandria University, was first secured before the beginning of the study. Also, an approval was obtained from (AUCH). (IRB 00010556) -(IORG 0008839)

Informed consents were obtained from parents / caregivers after explaining the study aim and procedures to ensure their full cooperation during samples collection through the study period. Parents / caregivers were assured about the data confidentiality and were informed of their right to withdraw any time.

A comprehensive sample of children with inclusion criteria including age range (3-12 years old) was targeted from the Alexandria University Children's Hospital. This hospital is the main center accessed by renal dialysis children with endstage renal failure diagnosed by a nephrologist. All the 
children present in the hospital in the period from October 2018 to April 2019 were examined and screened.

\section{Personal data and medical history}

The researcher first interviewed the parents /caregivers to record their personal data. Their medical data were collected from the patient's own medical records available at the hospital.

\section{Serum and salivary sample collection and analysis}

Unstimulated whole saliva was collected from each child for analysis of salivary urea, creatinine $(\mathrm{Cr})$, calcium $(\mathrm{Ca})$ and phosphorus $(\mathrm{P})$ concentrations before being connected to the hemodialysis machine between 8 to 9 am. The participants were instructed not to brush their teeth and not to take any food or drink for at least 1 hour prior to the saliva collection (18). Three ml of the saliva was collected in specimen sterile plastic containers. The specimens were stored in an icebox and transported to laboratory within 2 hours, for the processing and analysis of the samples.

Serum sample was taken from each child by the nursing staff before being connected to hemodialysis machine. Three ml of serum sample were collected and stored in an icebox and were transported to the laboratory within 2 hours for processing and analysis. Saliva samples were centrifuged at 2000rpm for 10 minutes, while serum samples were centrifuged for 5 minutes. The supernatant of the centrifuged saliva samples were obtained and analyzed and the rest of the sample was kept frozen at -80 degree centigrade till the end of the research period, in case we needed any recall of the tested samples.

\section{Laboratory Investigations}

Serum and salivary samples analysis were performed at Clinical Pathology Department, Faculty of Medicine, Alexandria University using Dimension RxL by Siemens (19). Serum tests including Urea, $\mathrm{Cr}, \mathrm{Ca}, \mathrm{P}$ and salivary tests including Urea, $\mathrm{Cr}$, Ca and $\mathrm{P}$ were recorded in all subjects.

\section{Statistical analysis}

Data were collected, tabulated and then subjected to the statistical analysis. Comparison between salivary and serum parameters was done using paired $\mathrm{T}$ - test for normally distributed variables urea and Ca and using Wilcoxon - signed rank test for non-normally distributed variables $\mathrm{Cr}$ and $\mathrm{P}$. While correlation between the same serum and salivary parameters was done using Pearson (normally distributed) and Spearman (non-normally distributed) correlations. The statistical analysis was done using IBM SPSS for windows, version 25.0. Armonk, NY: IBM Corp.

\section{RESULTS:}

A total of 20 children, who were undergoing hemodialysis, $50 \%(\mathrm{~N}=10)$ males, $50 \%(\mathrm{~N}=10)$ females participated in the study. The age of the participants ranged from 3 to 12 years with a mean age of $8.85 \pm 2.74$ years. When evaluating the etiology of the primary renal disorder among the participants it showed that hypoplastic kidneys was the most frequent cause of renal impairment among the study participants with $30 \%$ frequency, followed by congenital anomalies of kidney and urinary tract (CAKUT) 25\% and cystic kidney disease 20\%. Other conditions as Hemolytic Uremic Syndrome and hereditary nephritis were only $10 \%$ and $5 \%$ respectively. Unfortunately, 2 cases were passed undiagnosed. (Table 1) Comparison between studied serum and salivary parameters revealed that levels of $\mathrm{P}$ were significantly higher in saliva than in serum. However, levels of $\mathrm{Cr}$ and $\mathrm{Ca}$ showed significantly lower levels in saliva compared to serum (Table 2 and Figure1).

Regarding the correlation between studied serum and salivary parameters, there was a positive correlation ( $\mathrm{P}$ $<0.0001)$ between serum and salivary urea $(\mathrm{r}=0.79)$, as well as between serum and salivary $\mathrm{Cr}(\mathrm{r}=0.68)$. In contrast, a significant correlation between serum and salivary $\mathrm{P}$ was not detected. While, the correlation between serum and salivary Ca showed a non-significant weak positive correlation. (Table 3)

Table (1): Sample Description

\begin{tabular}{|c|l|}
\hline Variable & Frequency \\
\hline Age (mean \pm SD) & $8.85 \pm 2.74$ \\
\hline $\begin{array}{c}\text { Gender: } n(\%) \\
\text { • Males }\end{array}$ & $10(50 \%)$ \\
- Females & $10(50 \%)$ \\
\hline Etiology: n (\%) & \\
$\bullet \quad$ Hypoplastic Kidneys & $6(30 \%)$ \\
$\bullet \quad$ Cystic Kidney Diseases & $5(25 \%)$ \\
$\bullet \quad$ Hemolytic Uremic Syndrome & $4(20 \%)$ \\
$\bullet \quad$ Hereditary Nephritis & $2(10 \%)$ \\
$\bullet \quad$ Undiagnosed & $1(5 \%)$ \\
\end{tabular}

Table (2): Serum and Salivary Parameters Among the Study Participants

\begin{tabular}{|l|l|l|l|}
\hline \multicolumn{2}{|l|}{ Parameter level } & Mean \pm SD & P Value \\
\hline \multirow{2}{*}{ Urea $\left(\mathrm{CH}_{4} \mathrm{~N}_{2} \mathrm{O}\right)$} & Serum & $162.50 \pm 61.13$ & \multirow{2}{*}{$0.96^{a}$} \\
\cline { 2 - 3 } & Saliva & $163.00 \pm 61.46$ & \multirow{2}{*}{$<0.001^{* b}$} \\
\hline \multirow{3}{*}{ Creatinine (Cr) } & Serum & $7.95 \pm 2.77$ & \multirow{2}{*}{$<0.001^{* a}$} \\
\cline { 2 - 3 } Calcium (Ca) & Saliva & $0.60 \pm 0.46$ & \multirow{2}{*}{$<0.001^{* b}$} \\
\hline \multirow{2}{*}{ Phosphorus (P) } & Serum & $9.69 \pm 1.34$ & \\
\cline { 2 - 3 } & Saliva & $4.34 \pm 2.68$ & \\
\cline { 2 - 3 } & Serum & $6.57 \pm 2.42$ & \\
\cline { 2 - 3 } & Saliva & $20.14 \pm 6.15$ & \\
\hline
\end{tabular}

${ }^{a}$ Paired T test
${ }^{b}$ Wilcoxon Signed Rank test was used
${ }^{*}$ Statistically significant at $\mathrm{P} \leq 0.05$


Table (3): Correlation Between Serum and Salivary Parameters

\begin{tabular}{|l|l|l|}
\hline Parameter & $\begin{array}{l}\text { Correlation } \\
\text { Coefficient }\end{array}$ & P value \\
\hline Urea $\left(\mathrm{CH}_{4} \mathrm{~N}_{2} \mathrm{O}\right)^{a}$ & 0.79 & $<0.001^{*}$ \\
\hline Creatinine $(\mathrm{Cr})^{b}$ & 0.68 & $0.001^{*}$ \\
\hline Calcium $(\mathrm{Ca})^{b}$ & 0.10 & 0.69 \\
\hline Phosphorus $(\mathrm{P})^{a}$ & -0.008 & 0.97 \\
\hline
\end{tabular}

a Pearson Correlation

${ }^{b}$ Spearman Correlation

*Statistically significant at $\mathbf{P} \leq \mathbf{0 . 0 5}$

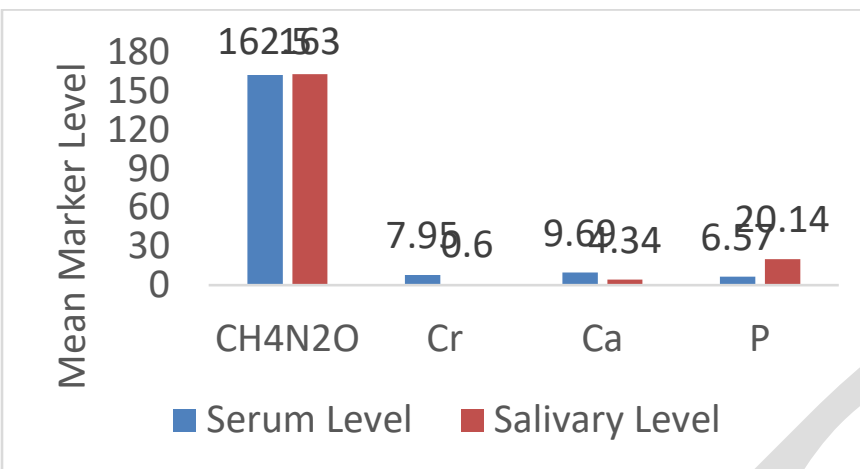

Figure 1: Serum and Salivary Parameters Among the Study Participants

\section{DISCUSSION:}

Excretory function of the kidney can be evaluated by assessing serum levels of compounds excreted by the kidney, usually the products of protein catabolism (urea and creatinine), which are important indicators of renal function alterations and also as kidney acts to maintain the constancy of body fluids, by regulating urine volume and composition. The level of serum electrolytes such as $\mathrm{Ca}, \mathrm{Na}, \mathrm{K}$ and $\mathrm{P}$ are also measured as an investigatory tool for diagnosis of renal disease and evaluation of the degree of renal impairment as well as assessing disease progression. Besides, Ca and $\mathrm{P}$ levels are known to be of utmost importance in the follow-up of bone mineral diseases in end stage renal diseases (ESRD) patients. Therefore, the parameters, which, were considered in our study, were urea, $\mathrm{Cr}$, Ca and $\mathrm{P}$ since these parameters are most widely accepted parameters to assess CKD as well as renal status. Taking into consideration the disadvantages of invasive serum collection method and simplicity of saliva collection, saliva could be considered an alternative to serum $(20,21)$.

Study results showed a significant correlation between salivary urea and creatinine levels with their serum levels. These findings are in agreement with the previous studies $(20,22-24)$. The correlation coefficient of salivary and serum urea level was 0.79 , while that of salivary and serum creatinine was 0.68 . Similar results were obtained by other studies $(20,25)$. This may be a result of greater filtration of urea in relation to creatinine due to lower molecular weight and size of urea at $60.03 \mathrm{D}$ and $0.26 \mathrm{~nm}(20)$ respectively , in relation with that of creatinine at $113 \mathrm{D}$ and $0.3 \mathrm{~nm}$ (26). Urea enters saliva from blood by the process of passive diffusion through acini of salivary glands (27). Therefore, our results along with other studies $(23,28)$ showed a positive correlation between salivary and serum urea levels.

Creatinine enters saliva from blood by ultrafiltration. Creatinine is a large molecule, with high molecular weight maintained at constant plasma levels by kidneys. It also displays low lipid solubility. Thus, in a healthy state under normal conditions it is not capable to diffuse easily through the cells and the tight intercellular junction of the salivary gland, due to its physical properties (29). However, in the diseased state probably alteration in the permeability of the salivary gland cells occurs (30). Additionally, the increased serum Cr levels in patients with CKD establish a concentration gradient that assists in diffusion of $\mathrm{Cr}$ from serum into saliva (31). Consequently, a good positive correlation was obtained between levels of $\mathrm{Cr}$ in saliva and serum in patients with CKD.

Salivary creatinine levels were found to be significantly lower when compared to serum Cr levels ( $\mathrm{P}=$ $0.001)$ which is consistent with other studies.(23, 28, 32, 33). Chiou et al and Lloyd et al found that salivary levels of $\mathrm{Cr}$ are only $10-15 \%$ of serum levels. This is due to relative non polar nature and large molecular weight of creatinine resulting in partial (incomplete) filtration (33).

These findings suggested that assessment of salivary urea and $\mathrm{Cr}$ could be an appropriate method for evaluating the efficacy of hemodialysis and monitoring CKD progression. It is believed that this may be advantageous particularly when dealing with pediatric patients on chronic hemodialysis. Regarding, diagnostic ability of saliva to replace serum, the diagnostic value of a new salivary test has to be compared with admitted diagnostic methods. The value of this new test will depend on how accurate it separates between the participants being tested into those with and without the disease in question (34).

On the other hand, levels of $\mathrm{Ca}$ in salivary samples were significantly lower than in serum samples, while salivary levels of phosphorus were significantly higher than serum levels $(P=0.001)$. Higher salivary $\mathrm{P}$ concentrations may be as a result of secretion of P from ductal cells (35). Serum and salivary Ca levels did show positive correlation, but analysis was found to be statistically insignificant. The study findings are in agreement with a study done by Tomas I et al in 2008 (22) .To elucidate the decline in serum and salivary calcium level, it is necessary to know that CKD progression causes a drop in 1,25 dihydroxycholecalciferol, an active metabolite of Vitamin D synthesized in the kidney which performs an important role in absorption of calcium from intestine. Thus, the levels of $\mathrm{Ca}$ in serum and saliva decline (20).

Salivary levels of $\mathrm{P}$ were significantly higher than serum levels $(P=0.001)$. This was in agreement with previous reports $(28,35)$. The increased salivary phosphorus levels could be a logical explanation for the compensatory activity of the salivary glands, which is an alternative excretion route to phosphorus, when the excretion ability of the kidney is 
diminished. Our results regarding increased levels of salivary $\mathrm{P}$ was in accordance with a study done by Savica et al.(35) The increase in serum and salivary $P$ levels can be justified by diminished phosphate load in the filtrate, where the filtered $\mathrm{P}$ is completely reabsorbed in the renal tubules (36). Thus, the level of $\mathrm{P}$ in serum increase. Consequently, these increased $\mathrm{P}$ ions bind with $\mathrm{Ca}$ ions forming calcium phosphate complex. Calcium phosphate complex can precipitate in soft tissue and in walls of blood vessels, increasing the risk for developing of cardiovascular diseases such as cardiovascular calcification, atherosclerosis, coronary artery disease and arrhythmias (37). Thus, hyperphosphatemia is dangerous in patients with CKD. Centered on the data from a previous study done by Savica et al.,in 2008(35), reporting that patients undergoing hemodialysis secrete between 300 and $600 \mathrm{mg}$ of salivary phosphate daily. The authors advocated that the measurement of salivary $\mathrm{P}$ can be helpful in deciding when hemodialysis is essential, avoiding unnecessary dialysis sessions. This fact may play a part in the rapid detection of clinical hyperphosphatemia (38). Thus, scheduled assessment of salivary $\mathrm{P}$ can be valuable in monitoring hyperphosphatemia in patients with CKD. Moreover, recognizing elevated levels of phosphorus in saliva can postulate the basis for the development of new drugs and help in launching strategies that stimulate the salivary excretion of $\mathrm{P}$, such as using of chewing gum with phosphate binders to reduce phosphorus reabsorption passing through the intestinal tract after ingestion of saliva containing high levels of phosphorus. Consequently, this will decrease the risk of hyperphosphatemia in patients with CKD, since this will help in elimination of $\mathrm{P}$ and avoid its reabsorption via intestinal tract (39).

Therefore, salivary Ca and P may be of limited use in evaluation of kidney disease progression and assessing patients with renal disease. Regarding other salivary parameters, further studies are essential to evaluate their role.

Consequently, we are likely to see the increased utilization of saliva as a diagnostic fluid. Accordingly, dentists will have greater involvement in the identification and monitoring of certain systemic disorders. While many questions remain, the prospective advantages of salivary analysis for the diagnosis of systemic disease suggest that further studies are highly demanded. Thus, to make salivary diagnostic a clinical reality, further scientific validation is needed for each disease.

The limitations of this study could be based on the small sample size and the lack of parallel arm for comparison as well as pre and post hemodialysis evaluations of salivary parameters at different time intervals.

\section{CONCLUSIONS:}

Analysis of salivary creatinine and urea in patients with chronic kidney disease mirrored their levels in serum, and therefore could be used as a noninvasive method to detect their levels in patients with chronic kidney disease.

\section{CONFLICT OF INTEREST:}

The authors declare that they have no conflicts of interest.

\section{REFERENCES}

1. Becherucci F, Roperto RM, Materassi M, Romagnani P. Chronic kidney disease in children. Clin. Kidney J. 2016;9:583-91.

2. Schnaper HW. Pathophysiology of Progressive Renal Disease in Children. In: Avner ED, Harmon WE, Niaudet P, Yoshikawa N, Emma F, Goldstein SL, editors. Pediatric Nephrology. Berlin, Heidelberg: Springer Berlin Heidelberg; 2016. p. 2171-206.

3. Baum M. Overview of chronic kidney disease in children. Current opinion in pediatrics. 2010;22:158-60.

4. Hill NR, Fatoba ST, Oke JL, Hirst JA, O'Callaghan CA, Lasserson DS, et al. Global Prevalence of Chronic Kidney Disease - A Systematic Review and Meta-Analysis. PloS one. 2016;11:e0158765-e.

5. Harambat J, van Stralen KJ, Kim JJ, Tizard EJ. Epidemiology of chronic kidney disease in children. Pediatr. Nephrol (Berlin, Germany). 2012;27:363-73.

6. Nunes LAS, Mussavira S, Bindhu OS. Clinical and diagnostic utility of saliva as a non-invasive diagnostic fluid:. Biochemia medica. 2015;25:177-92.

7. Chojnowska S, Baran T, Wilinska I, Sienicka P, CabajWiater I, Knas M. Human saliva as a diagnostic material. ADV MED SCI-POLAND. 2018;63:185-91.

8. Inker LA, Astor BC, Fox CH, Isakova T, Lash JP, Peralta CA, et al. KDOQI US commentary on the 2012 KDIGO clinical practice guideline for the evaluation and management of CKD. Am J Kidney Dis: the official journal of the National Kidney Foundation. 2014;63:713-35.

9. Esmaeeli A, Esmaeeli M, Ebrahimi M, Nasehi A. Association between oral findings and laboratory tests in children and adolescents undergoing dialysis: A crosssectional study. J Clin Exp Dent. 2018;10:e462.

10.Tong P, Yuan C, Sun X, Yue Q, Wang X, Zheng S. Identification of salivary peptidomic biomarkers in chronic kidney disease patients undergoing haemodialysis. Clinica chimica acta; international journal of clinical chemistry. 2019;489:154-61.

11. Greenberg BL, Glick M, Frantsve-Hawley J, Kantor ML. Dentists' attitudes toward chairside screening for medical conditions. J Am Dent Assoc. 2010;141:52-62.

12. Kaufman E, Lamster IB. The diagnostic applications of saliva--a review. Critical reviews in oral biology and medicine : an official publication of the American Association of Oral Biologists. 2002;13:197-212.

13. Pfaffe T, Cooper-White J, Beyerlein P, Kostner K, Punyadeera C. Diagnostic potential of saliva: current state and future applications. Clin Chem. 2011;57:675-87.

14.Wang A, Wang CP, Tu M, Wong DTW. Oral Biofluid Biomarker Research: Current Status and Emerging Frontiers. Diagnostics (Basel, Switzerland). 2016;6:45.

15. Ai OY, P. P, Gokulraj S. Saliva as Biomarkers. J Dent Educ. 2018:5. 
16. Baum BJ, Yates JR, 3rd, Srivastava S, Wong DTW, Melvin JE. Scientific frontiers: emerging technologies for salivary diagnostics. Adv Dent Res. 2011;23:360-8.

17. Arunkumar S, Arunkumar J, Krishna N, Burde, Shakuntala G, Shantala A, et al. Developments in diagnostic applications of saliva in oral and systemic diseases-A comprehensive review2014. 372-87 p.

18. Chiappin S, Antonelli G, Gatti R, Elio F. Saliva specimen: a new laboratory tool for diagnostic and basic investigation. Clinica chimica acta. 2007;383:30-40.

19. Ghoshal AK, Soldin SJ. Evaluation of the Dade Behring Dimension RxL: integrated chemistry system-pediatric reference ranges. Clinica chimica acta; international journal of clinical chemistry. 2003;331:135-46.

20.Bagalad BS, Mohankumar KP, Madhushankari GS, Donoghue M, Kuberappa PH. Diagnostic accuracy of salivary creatinine, urea, and potassium levels to assess dialysis need in renal failure patients. Dent Res J (Isfahan). 2017;14:13-8.

21. Ahmadi-Motamayel F, Davoodi P, Dalband M, Hendi SS. Saliva as a mirror of the body health2010. 1-15 p.

22. Tomas I, Marinho JS, Limeres J, Santos MJ, Araujo L, Diz P. Changes in salivary composition in patients with renal failure. Arch Oral Biol . 2008;53:528-32.

23. Xia Y, Peng C, Zhou Z, Cheng P, Sun L, Peng Y, et al. [Clinical significance of saliva urea, creatinine, and uric acid levels in patients with chronic kidney disease]. Zhong nan da xue xue bao Yi xue ban . J CENT SOUTH UNIV. 2012;37:1171-6.

24. Pham TAV. Validation of the salivary urea and creatinine tests as screening methods of chronic kidney disease in Vietnamese patients. Acta Odontol Scand. 2017;75:551-6.

25. Bader R, Kora M, El-Shalakany A, Mashal B. Clinical significance of saliva urea and creatinine levels in patients with chronic kidney disease. Menoufia Med. J 2015;28:406-10.

26. Guignard JP, Drukker A. Why do newborn infants have a high plasma creatinine? Pediatrics. 1999;103:e49.

27. Carco P, Canciullo D. Urea excretion through the human salivary glands. Ann. Otol. Rhinol. Laryngol. 1958;67:1050-65.

28. Yajamanam N, Vinapamula KS, Sivakumar V, Bitla AR, Rao PV. Utility of saliva as a sample to assess renal function and estimated glomerular filtration rate. Saudi J Kidney Dis Transpl : an official publication of the Saudi Center for Organ Transplantation, Saudi Arabia. 2016;27:312-9.
29. Guyton AC, Hall JE.The body fluids and kidneys In: Schmidt W, editor. , ed. Textbook of Medical Physiology. Philadelphia, PA: Elsevier Saunders; 2006:291-415

30. Ivanovski K, Naumovski V, Kostadinova M, Pesevska S, Drijanska K, Filipce V. Xerostomia and salivary levels of glucose and urea in patients with diabetes. Prilozi. 2012;33:219-29.

31. Nakahari T, Yoshida H, Imai Y. Transepithelial fluid shift generated by osmolarity gradients in unstimulated perfused rat submandibular glands. Exp Physiol. 1996;81:767-79.

32. Venkatapathy R, Govindarajan V, Oza N, Parameswaran S, Pennagaram Dhanasekaran B, Prashad KV. Salivary creatinine estimation as an alternative to serum creatinine in chronic kidney disease patients. Int. J. Nephrol. 2014:742724.

33. Temilola, D. O., Bezuidenhout, K., Erasmus, R. T., Stephen, L., Davids, M. R., \& Holmes, H. (2019). Salivary creatinine as a diagnostic tool for evaluating patients with chronic kidney disease. BMC nephrology, 20(1), 387.

34. Brown Connolly NE. A better way to evaluate remote monitoring programs in chronic disease care: receiver operating characteristic analysis. Telemed J E Health : the official journal of the American Telemedicine Association. 2014;20:1143-9.

35. Savica V, Calo L, Santoro D, Monardo P, Granata A, Bellinghieri G. Salivary phosphate secretion in chronic kidney disease. J Ren Nutr : the official journal of the Council on Renal Nutrition of the National Kidney Foundation. 2008;18:87-90.

36. Malamud D. Saliva as a diagnostic fluid. Dent Clin North Am.. 2011;55:159-78.

37. Gansevoort RT, Correa-Rotter R, Hemmelgarn BR, Jafar TH, Heerspink HJ, Mann JF, et al. Chronic kidney disease and cardiovascular risk: epidemiology, mechanisms, and prevention. Lancet (London, England). 2013;382:339-52.

38. Streja E, Lau WL, Goldstein L, Sim JJ, Molnar MZ, Nissenson AR, et al. Hyperphosphatemia is a combined function of high serum PTH and high dietary protein intake in dialysis patients. Kidney Int Suppl. 2013;3:462-8.

39. Savica V, Calo LA, Santoro D, Monardo P, Santoro G, Muraca U, et al. Salivary glands: a new player in phosphorus metabolism. J Ren Nutr : the official journal of the Council on Renal Nutrition of the National Kidney Foundation. 2011;21:39-42. 